\title{
Resveratrol treatment reduces apoptosis and morphological alterations in cisplatin induced testis damage
}

\author{
Nagehan ÖZYILMAZ YAY 1 (D), Göksel ŞENER 2 (D), Feriha ERCAN 1 * (D) \\ 1 Department of Histology and Embryology, School of Medicine, Marmara University, İstanbul, Turkey \\ 2 Department of Pharmacology, Faculty of Pharmacy, Marmara University, İstanbul, Turkey \\ Corresponding author: E-mail: eferiha@hotmail.com; fercan@marmara.edu.tr (F.E.); Tel. +90-533-335 2018
}

Received: 09 January 2019 / Revised: 26 March 2019 / Accepted: 28 March 2019

\begin{abstract}
Cisplatin commonly used as a chemotheropotic agent however, it is associated with numerous side effects such as reproductive cytotoxicity. It causes spermatogenic cell death and DNA damage in spermatozoa via the formation of reactive oxygene species. Resveratrol (3,5,4'-trans-trihydroxystilbene), a natural phytoalexin, is a potent antioxidant agent, present in a wide variety of dietary sources including grapes, plums and peanuts. The aim of present study to evaluate the beneficial effects of resveratrol on cisplatin induced testis damage. Male Sprague Dawley rats were used in the study and four experimental groups were formed as: 1- saline applied control, 2- resveratrol applied control, 3- cisplatin and 4- cisplatin+resveratrol groups. Following a single dose of cisplatin (7 mg/ $\mathrm{kg}$ i.p.), either saline or resveratrol $(10 \mathrm{mg} / \mathrm{kg}$, orally) was administered for 5 days. Testis samples were prepared for histopathological and ultrastructural evaluations, cell proliferation and apoptosis. Tissue malondialdehyde (MDA), glutathione (GSH) levels and myeloperoxidase (MPO) activity were determined biochemically. Degenerated and atrophic tubules of tissue, apoptotic cells, MDA level and MPO activity were increased although proliferation index and GSH level were decreased in cisplatin group. Degenerated tight junctions between the Sertoli cells and vacuole formation in germinal epithelial cells were also revealed at this group. However, resveratrol treatment reduced degenerated and atrophic tubules, apoptotic cells, vacuole formation in germinal epithelial cells, MDA level and MPO activity and increased proliferation index and GSH level in testis. These results showed that resveratrol ameliorates cisplatin induced testis injury by the impairment of oxidative stress and apoptosis.
\end{abstract}

KEYWORDS: Cisplatin; resveratrol; testis; apoptosis; cell proliferation; ultrastructure.

\section{INTRODUCTION}

Cisplatin (Cis) is a highly active antineoplastic agent commonly used in the treatment of several types of human cancer such as, testicular [1] ovarian [2], prostate [3] and bladder carcinoma [4], neuroblastoma [5] and head-neck carcinoma [6]. However, the clinical use of Cis is often restricted because of its many side effects, such as nephrotoxicity [7], ototoxicity [8], neurotoxicity [9], cardiotoxicity [10] and gonodal toxicity [11]. Also an increase of apoptosis in germ cells is seen because of the side effects of Cis and the other chemoterapeutics on testis $[12,13]$. It was observed that Cis treatment altered oxidative markers such as increase of malondialdehyde (MDA), and decrease of endogenous gluthatione (GSH) which cause disturb the organs' pathophysiology in many systems including urogenital system [14].

Exogenous many antioxidants such as melatonin [15] and quercetin [16] have been investigated as protecting against oxidative damage and combined with chemotherapeutics. Resveratrol (3,40,5-transtrihydroxystilbene, RVT), a potent antioxidant, is a phytoalexin and present in plants such as grapes, peanuts berries and pines. RVT reduces lipid peroxidation by its free radical scavenger, improves the activities of a variety of antioxidant enzymes and prevents DNA damage [17]. RVT increases endogenous antioxidant levels such as GSH, superoxide dismutase (SOD), catalase (CAT), glutathion reductase by alleviating oxidative damage [18]. RVT also has antimutagenic, antiproliferative and anticarcinogenic effects besides its antioxidant effects [19]. According to these findings, antioxidants proposed to evaluate protective and therapeutic effects on tissue damage caused by chemotherapotics.

Exessive generation of reactive oxygen speices (ROS) can cause testicular damage. Cisplatin treatment also increases formation of ROS in testis which causes the seminiferous tubule damage with germ cell

How to cite this article: Özyılmaz Yay N, Şener G, Ercan F. Resveratrol treatment reduces apoptosis and morphological alterations in cisplatin induced testis damage. J Res Pharm. 2019; 23(4): 621-631. 
apoptosis, disfunction of Leydig cells and disorder of testicular stereodogenesis and culminating infertility [20]. For protecting the testicular damage from the side effects of cisplatin many antioxidant substances such as lycopene and ellagic acid [13], acetyl L-carnitine [21] and apocynin [22] were investigated in rats.

In this study we aimed to investigate cisplatin's gonodotoxic side effects in the rat testis and the possible beneficial antioxidant and antiapoptotic effects of RVT by histochemical, ultrastructral and biochemical methods.

\section{RESULTS}

\subsection{Histopathological evaluation}

Normal seminiferous tubules and spermatogenic cells in testis were observed in the control and RVT groups. In the Cis group degenerative, regressive and athrophic tubules were increased. Also, many many seminiferous tubules with cellular debris in the lumen, increase of basement membrane thickness and connective tissue elements in the interstitial area were observed in this group. In the Cis+RVT group, the number of atrophic and degenerative seminiferous tubules decreased significantly. Most of the seminiferous tubules were in normal morphology (Figure 1).

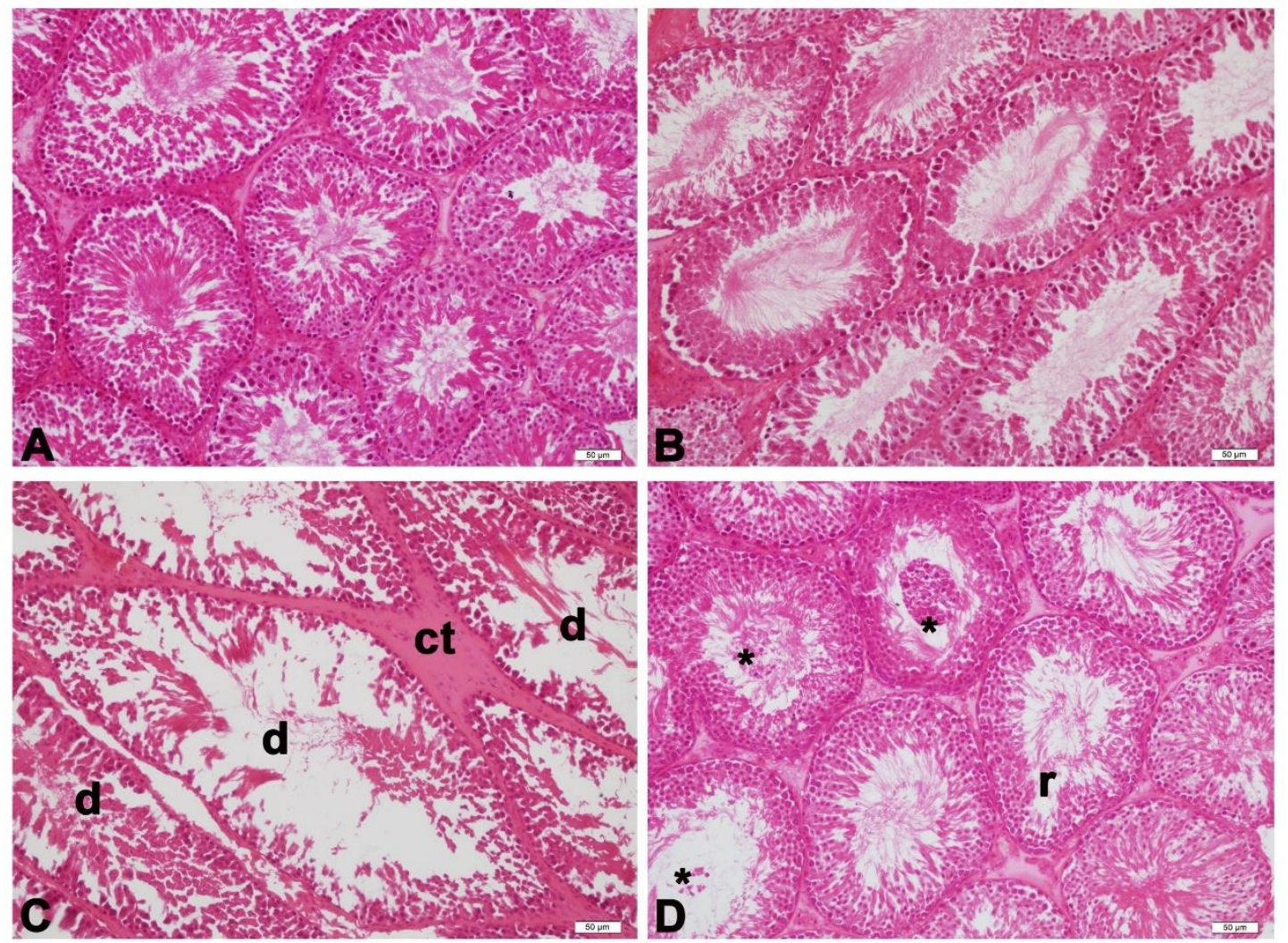

Figure 1. Representative light micrographs of testicular tissue in experimental groups. A: Regular seminiferous tubules with germinal epithelium are seen in control (A) and RVT applied control (B) groups. Degenerated seminiferous tubules (d) with dilatation between the germinal epithelial cells, increase of connective tissue elements (ct) in interstitial area are seen in Cis group (C). Cellular debris $\left(^{*}\right)$ in lumen seminiferous tubules and regresive seminiferous tubule $(r)$ are seen in Cis+RVT group (D). H\&E staining.

The diameter of seminiferous tubules was $319,4 \pm 13,3 \mu \mathrm{m}$ in control group and $310,6 \pm 11,8 \mu \mathrm{m}$ in RVT group. There were significant decrease in seminiferous tubule diameter in Cis group $(275,2 \pm 10,7 \mu \mathrm{m})$ compare with the control group. However, the seminiferous tubule diameter was significantly increased in Cis+RVT group $(292,8 \pm 9,7 \mu \mathrm{m})$ compared with Cis group (Figure 2A).

Histopathological scoring results are shown in Figure 2B. In the Cis group, atrophic $(p<0.001)$, degenerative $(p<0.001)$ and regressive $(p<0.001)$ seminiferous tubules were significantly increased compared with the control group. In the Cis+RVT group, the number of normal tubules $(\mathrm{P}<0.01)$ and regressive tubules 
$(p<0.05)$ were significantly increased and degenerative $(p<0.001)$ and atrophic tubules $(p<0.001)$ were significantly decreased compared with the Cis group (Figure $2 \mathrm{~B}$ ).

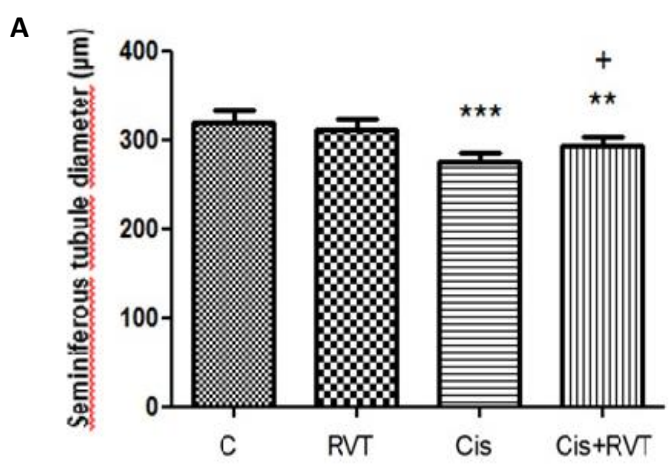

B

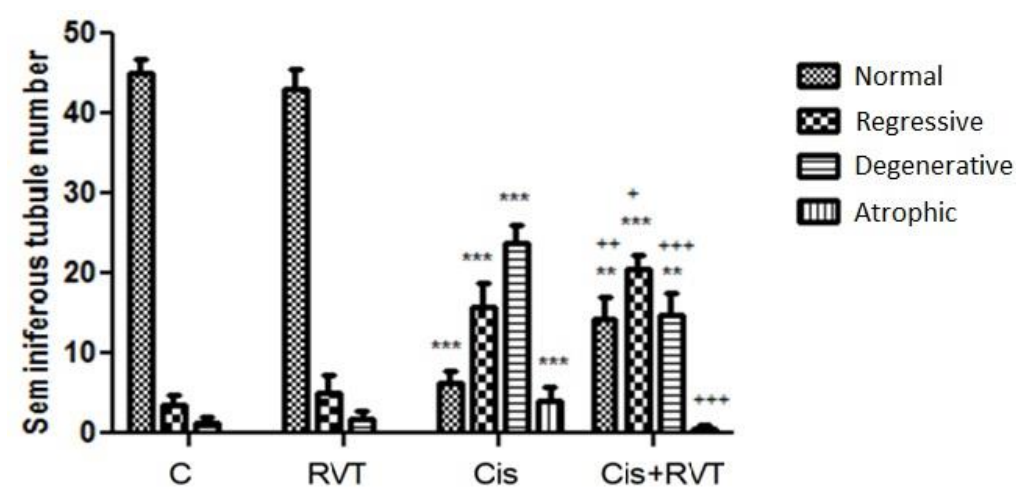

C

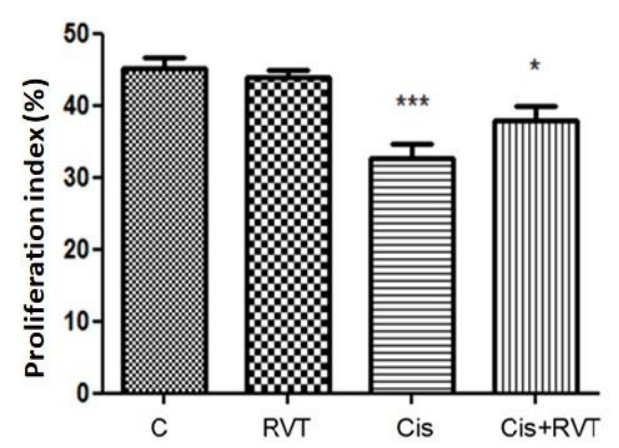

D

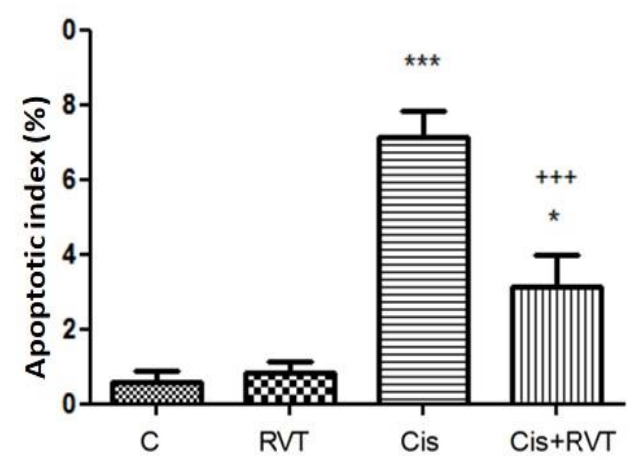

Figure 2. Seminiferous tubule diameter (A) and histopathology scores (B), proliferative index (C) and apoptotic index (D) in experimental groups. *: $p<0.05,{ }^{* *}$ : $p<0.01,{ }^{* * *}: p<0.001$ versus control group. + : $p<0.05$, ++: $\mathrm{p}<0.01,+++\mathrm{p}<0.001$ versus Cis group. 


\subsection{Evaluation of PCNA assay}

Brown-coloured PCNA + cells were observed in each seminiferous tubules in all experimental groups (Figure 3). Proliferation index was significantly decreased at Cis $(\mathrm{p}<0.001)$ group compared to control group. However increase of proliferation index was observed at Cis $+R V T$ group $(p<0.001)$ compared with Cis group (Figure 2C).

\subsection{Evaluation of TUNEL assay}

Brown-coloured TUNEL+ cells in seminiferous tubules were observed in all groups (Figure 4). The number of seminiferous tubules with three or more TUNEL+ cells was significantly increased at Cis $(\mathrm{p}<0.001)$ group. However seminiferous tubules with three or more TUNEL+ cells was significantly decreased at Cis+RVT group $(\mathrm{p}<0.001)$ compared with Cis group. (Figure 2D).
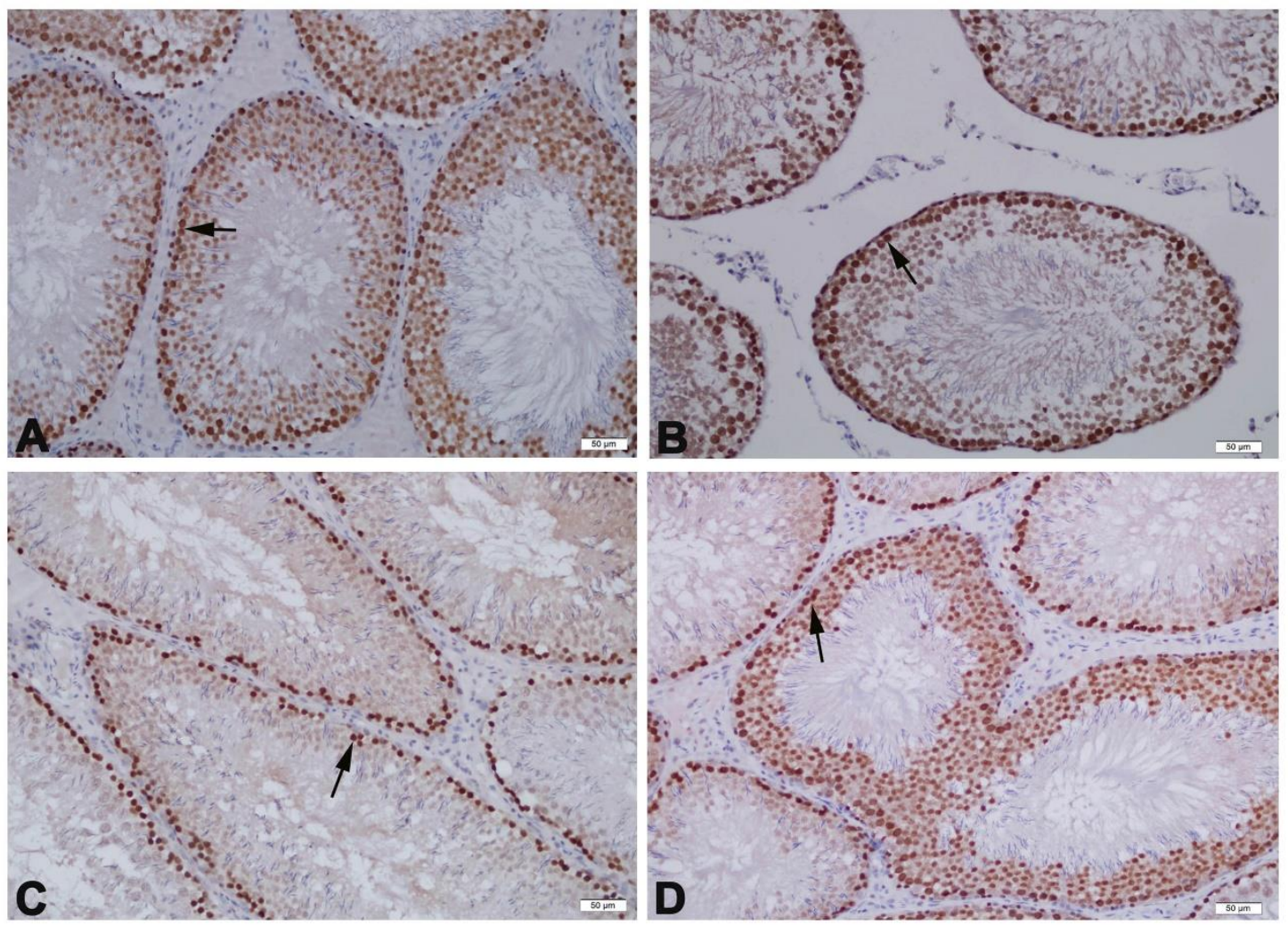

Figure 3. Representative light micrographs of PCNA stained testicular tissue in experimental groups. Regular seminiferous tubules with PCNA positive spermatogenic cells (arrow) in control (A) and RVT applied control (B) groups; decrease number of PCNA positive cells (arrow) in seminiferous tubules in Cis group (C); regular seminiferous tubules with many PCNA positive cells (arrow) in Cis+RVT group (D) are seen.

\subsection{Electron microscopic evaluation}

Normal seminiferous tubules with regular tight junctions between the Sertoli cells were seen in the control and RVT groups. Dilatation in the intercellular space near the basal lamina and severe large vacuoles in the cytoplasm of spermatogonia and Sertoli cells were observed in the Cis group. Regular ultrastructure of spermatogonia and Sertoli cells with tight junctions were observed in most regions of the Cis+RVT group. Even though most of the tubules showed regular ultrastructure with tight juntions of Sertoli cells, some tubules consisted of vacuole formation in the cytoplasm of Sertoli cells in this group (Figure 5).

\subsection{Evaluation of MDA and GSH levels and MPO activity}

The MDA levels in testis were significantly higher in the Cis group $(p<0.001)$ than in the control group, while treatment with RVT significantly reduced MDA level $(\mathrm{P}<0.05)$ comparing to Cis group (Figure 6A). Cis caused substantial depletion of tissue GSH level $(\mathrm{p}<0.001)$. RVT treatment increased GSH level, but this 
increase was not found significant (Figure 6B). The MPO activity was significantly increased in Cis group $(\mathrm{p}<0.001)$ than the control group $(\mathrm{p}<0.001)$ while treatment with RVT $(\mathrm{p}<0.001)$ significantly reduced MPO activity (Figure 6C).
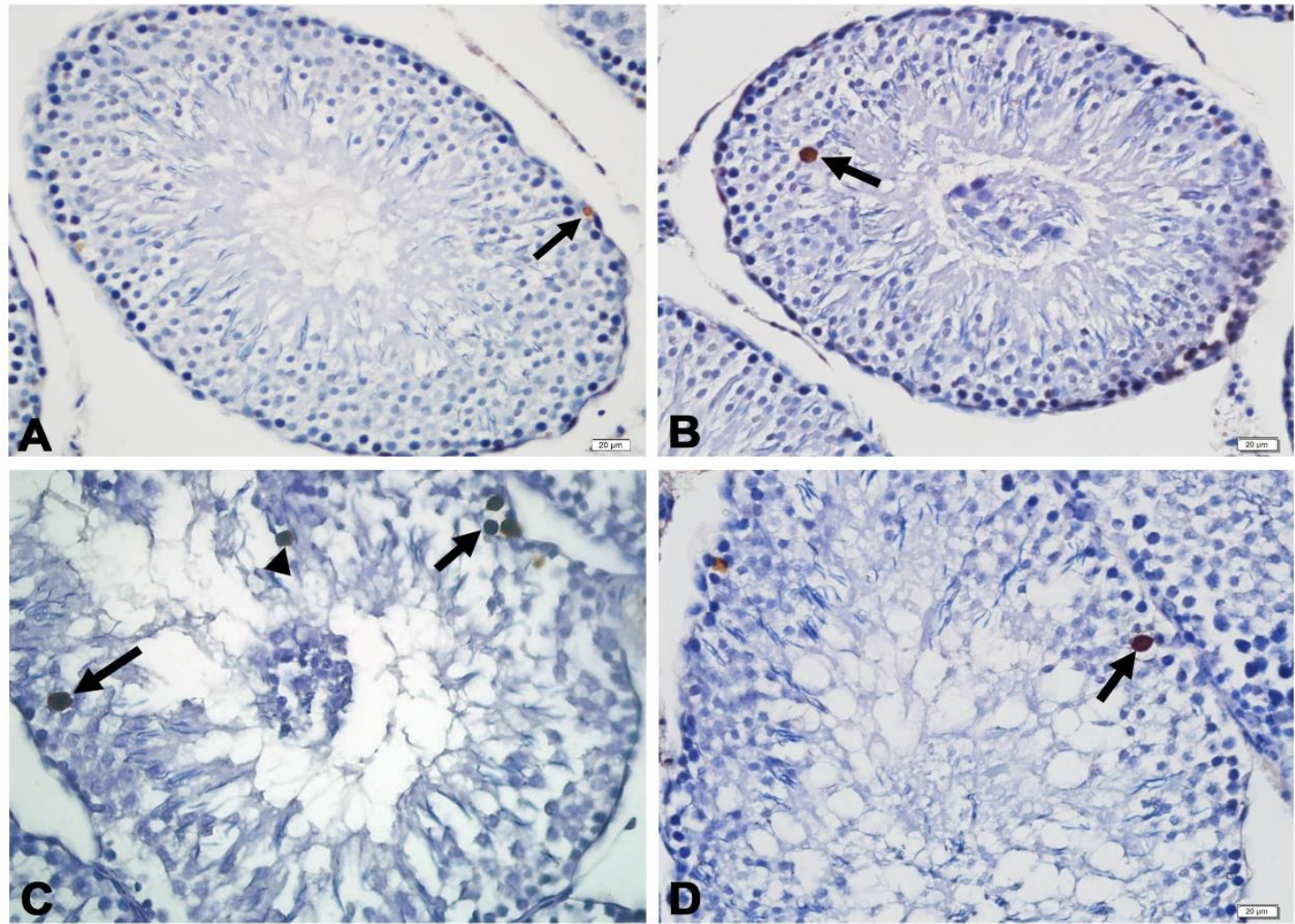

Figure 4. Representative light micrographs of TUNEL stained testis tissues in experimental groups. A few number of TUNEL positive cells (arrow) in control (A) and RVT applied control (B) groups; increase number of TUNEL positive cells (arrow) in germinal epithelium and luminal region (arrowhead) of Cis group (C) and decrease number of TUNEL positive cells (arrow) in the Cis+RVT group (D) are seen.

\section{DISCUSSION}

The present study showed that Cis induces histological alterations with a decrease of testicular diameter, an increase of regressive, degenerative and atrophic seminiferous tubules, decrease of spermatogenic cell proliferation and increase of apoptosis. Moreover, Cis induces oxidative injury and inflammatory activity with an increase of MDA level and MPO activity and depletion of antioxidant GSH level. RVT treatment amelioritaes all these histological and biochemical alterations and protects against Cisinduced testicular damage.

Cisplatin is one of the most effective antineoplastic agent quite used in the treatment of several types of cancers including urogenital system carcinoma. However, Cis has side effects such as nephrotoxicity, hepatotoxicity, cardiotoxicity, ototoxicity and gonadal toxicity. Cis induced tissue injury mechanisms has not been well-explained. Cis treatment causes cytotoxicity including formation of ROS, DNA damage, induction of apoptosis and inflammation, reduction of DNA synthesis and mitosis [23, 24]. Also, studies demonstrated that Cis promotes histopathological changes in testicular tissue, decrease of seminiferous tubule diameter, spermatogenic cell proliferation and increase of apoptosis in seminiferous tubules [21,25]. In this present study a single dose $(7 \mathrm{mg} / \mathrm{kg})$ administration of Cis were significantly decreased seminiferous tubule diameter and PCNA positive cells in Cis group. Degenarated and atrophic tubules, and apoptotic cells in germinal epitelium were significantly increased in Cis group. RVT treatment enhanced the seminiferous tubule diameter with decrease of atrophic tubules by inbition of apoptosis. 

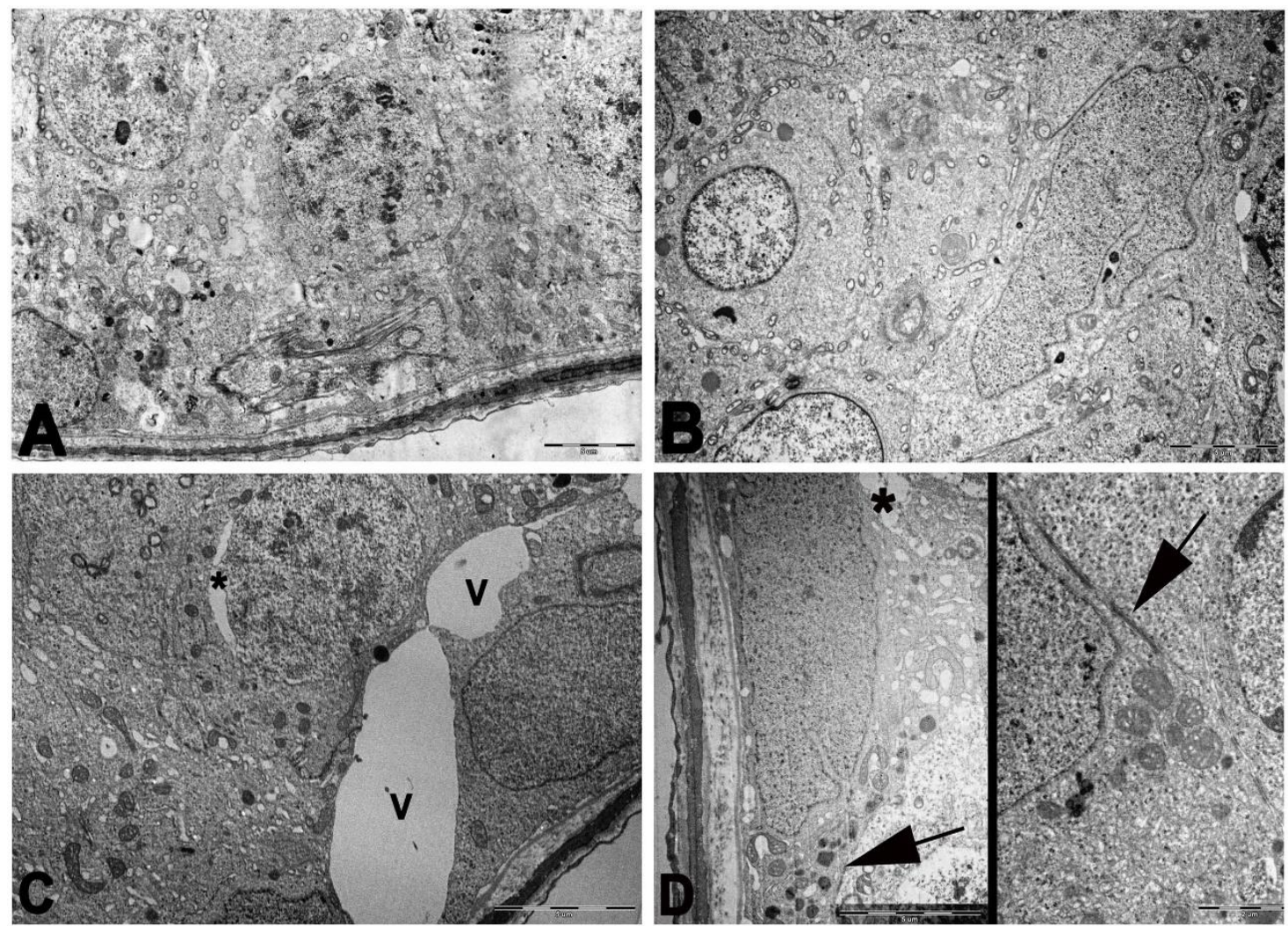

Figure 5. Representative electron micrographs of testicular tissue in experimental groups. Regular basal lamina, germinal cells and Sertoli cells with tight junctions in control (A) and RVT applied control (B) groups; large vacuole formation $(\mathrm{v})$ around tight junctions in the intercellular spaces and intracytoplasmic vacuolar structures $\left(^{*}\right)$ in the Cis group $(\mathbf{C})$; regular morphology of basal lamina, tight junctions $(\rightarrow)$ and some intracellular vacuoles $\left(^{*}\right)$ in the RVT+ Cis group (D) are seen.

It is known that Cis treatment promotes oxidative stress by increasing ROS. Cis treatment increased the formation of MDA, an index of lipid peroxidation, and decreased of endogenous antioxidant enzyme as GSH in the testes. Moreover, Cis treatment causes the inflammation by the accumulation of leukocytes in kidney and liver tissues [26]. Activated leukocytes such as neutrophils release reactive oxygen metabolites and MPO into the extracellular fluid. Neutrophil infiltration occurs in the acute inflammation and increases the MPO activity. Cis application may cause testis damage by increase of MDA level, inflammation and the MPO activity [27]. It was shown that treatment with different antioxidants such as rutin [28] and melatonin [29] reduces ROS generation as well as MPO activity in different oxidative injury models. In our study increase of MDA level and MPO activity and a decrease of GSH level were observed in the Cis group. RVT treatment ameliorated MDA production and MPO activity and replenished GSH level in Cis induced oxidative damage in rat testis.

Previous studies demonstrated that Cis inhibits tumor growth by inducing apoptosis in patients [30] and Cis induces apoptosis in rat testis and spermatozoa [31-33]. Several studies showed that Cis treatment increases the formation of oxidative stress, DNA fragmentation and induceses apoptosis in testis, and different antioxidants and antioxidant rich extracts such as rutin [34], Ginkgo biloba extract [27], and Eugenia jambolana extract [35] inhibits apoptosis in Cis induced testis damage. It was shown that RVT inhibits apoptosis in Cis induced kidney injury [36], ischemia reperfusion induced cardiac injury [37] and acrylamide- induced oxidative stress in many tissues [38]. In this study, we observed that RVT inhibits the formation of apoptosis in Cis induced testis injury by the regulation of oxidant/antioxidant balance.

RVT's antioxidant, antiinflammatory and antiapototic roles were studied in different experimental testis injury models such as ischemia/perfusion [39], cadmium chloride treatment [40] and polyvinyl chloridetreatment [41]. It was shown that RVT protects the Cis induced testis damage in mice by the inhibition of oxidative stress [42]. Furthermore, it was observed that 45 days RVT $(20 \mathrm{mg} / \mathrm{kg}$ body weight) treatment ameliorates oxidant, steroidogenic and spermatogenic activity which was detoriated by the injection of 3 $\mathrm{mg} / \mathrm{kg}$ Cis for 3 days [43]. Parallel to this study's results, we observed that RVT treatment enhanced 
antioxidant activity, testis morphology, inhibited apoptosis and inflammation from side effects of a Cis. Additionally our ultrastructural results showed that RVT amelioriated the germinal epithelial cells, Sertoli cells and tight junctions from a destructive effects of Cis.

A

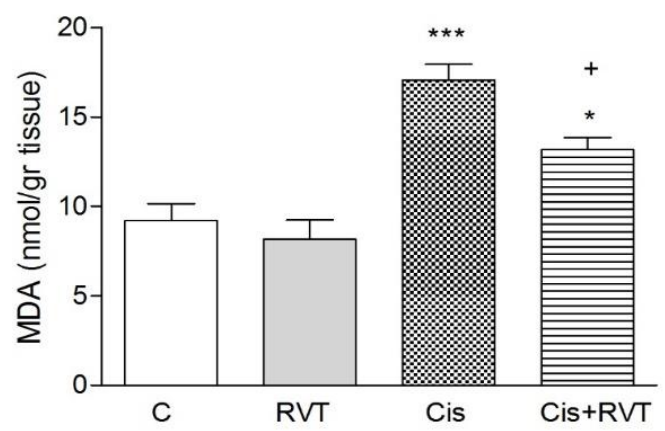

B

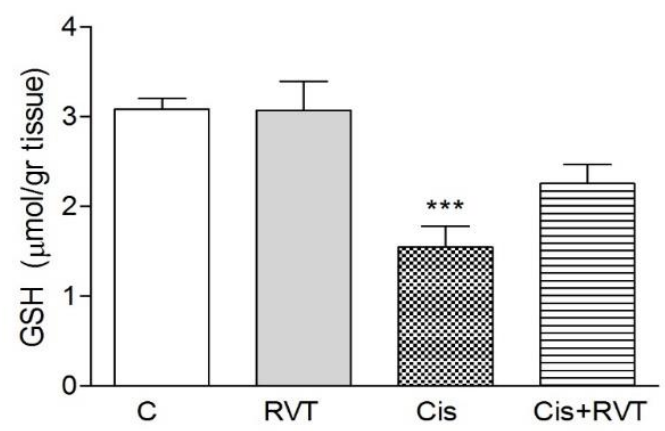

C

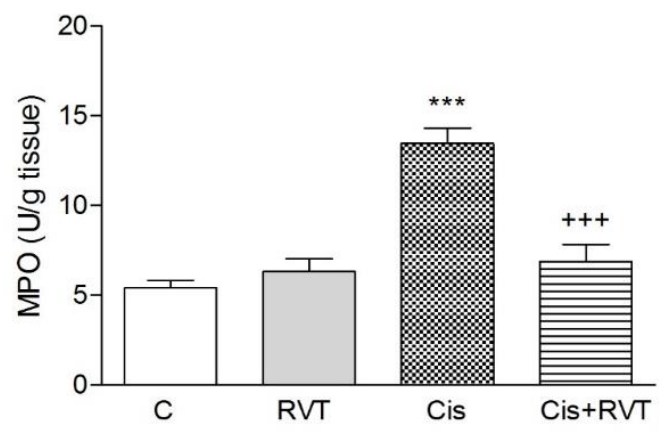

Figure 6. MDA (A) and GSH (B) levels, and MPO (C) activity in experimental groups. * ${ }^{*}<0.05,{ }^{* * *}$ : $<<0.001$ versus control group. $+: \mathrm{p}<0.05,+++$ : $\mathrm{p}<0.001$ versus $\mathrm{Cis}$ group.

\section{CONCLUSION}

Cis treatment caused decrease of spermatogenic cell line, endogenous GSH level, ultrastructural degeneration of both spermatogenic and Sertoli cells, increase of oxidative, inflammatory and apoptotic activity and RVT amelioriates all these parameters in testis. This study showed that RVT amelioriates Cis induced testis damage by the antioxidant and antiapoptotic effects. It is concluded that, using of RVT might prevent Cis induced testis damage by the inhibition of ROS formation and apoptosis.

\section{MATERIALS AND METHODS}

\subsection{Animals}

Adult male Sprague-Dawley rats were housed individually in a light- and temperature-controlled room on a 12-h/12-h light-dark cycle and fed a standard pellet lab chow. All experimental protocols were approved by the Animal Care and Use Committee of the Marmara University (21.11.2013-106.2013.mar). 


\subsection{Experimental groups}

Twenty-eight rats were divided into four groups: 1) Control (n=7) , 2) RVT (n=7), 3) Cis (n=7) , 4) Cis+RVT (n=7). We applied either saline or $10 \mathrm{mg} / \mathrm{kg}$ RVT orally for 5 days after a single dose of $7 \mathrm{mg} / \mathrm{kg}$ i.p. cisplatin to the Cis groups. Cis [22] and RVT [19] doses were decided according to our previous studies. Only saline or RVT was applied to the control groups. After 5 days, rats were decapitated under ether anesthesia and testis tissues were removed for histochemical, ultrastructural and biochemical evaluation.

\subsection{Light microscopic preparation and histopathological scoring}

The right testes of rats were removed, and fixed in Bouin's solution for $48 \mathrm{~h}$ and then processed routinely for paraffin embedding. Approximately $4 \mu \mathrm{m}$ thick paraffin sections stained with hematoxylin and eosin (H\&E) for histopathological analysis. Fifty seminiferous tubules from a secton of mid-testicular region for each animal were photographed and evaluated for tubule diameter and histopathological scoring by the NIH Image Analysis (IMAGE J, National Institutes of Health, Bethesda, MD, USA) program. Modified Hess's histopathological scoring was evaluated as normal, regressive, degenerative or atrophic tubules [44].

\subsection{Proliferating Cell Nuclear Antigen Method}

The samples from left testes of all groups were fixed with $10 \%$ neutral formaldehyde, processed routinelly for paraffin embedding. Approximately $5 \mu \mathrm{m}$ thick sections were deparaffinized, rehydrated in a graded series of ethanol, and immersed in $3 \%$ hydrogen peroxide for $5 \mathrm{~min}$ twice. Then boiled in citrate buffer (10mM; pH 6.0) for 20 minutes for proliferating cell nuclear antigen (PCNA) retrieval. Following washing in PBS 2X5 min slides were incubated with blocking solution (invitrogen PCNA staining kit, cat. No.93-1143) for $10 \mathrm{~min}$. Sections were incubated in a humidified chamber with mouse anti-PCNA primary antibody (ready to use, Invitrogen PCNA Staining Kit cat. no.93-1143) overnight at 4 to $8{ }^{\circ} \mathrm{C}$. Following washing with PBS, slides were incubated with biotinlated secondary antibody for $10 \mathrm{~min}$, washed with PBS, incubated with streptavidin peroxidase for $10 \mathrm{~min}$. After washing with then washing with PBS, the slides were incubated with 3, 3diaminobenzidine tetrahydrochloride dihydrate $(\mathrm{DAB})$ for $5 \mathrm{~min}$. Slides were stained with hematoxylin and mounted with entellan (Merck, Darmstadt, Germany). For evaluation of proliferative index randomly selected 20 seminiferous tubules were counted both PCNA+ and PCNA- germ cells. Proliferative index were calculated as PCNA + cells/total cells in each seminiferous tubules.

\subsection{Terminal transferase-mediated dUTP-biotin Nick end Labeling Method}

The apoptotic cells were evaluated by terminal transferase-mediated dUTP-biotin Nick end Labeling (TUNEL) accordaning with the manufacturer's directive (Apoptag Plus Peroxidase in situ Apoptosis kit, Chemicon International, S7101, Temecula, CA, USA). The procedure was as follows: every fifth parafine sections (a total of five sections from each animal) was incubated with proteinase $\mathrm{K}$ washed with distilled water and incubated with $3 \%$ hydrogen peroxide in PBS. The sections were then washed with PBS, put in the balance buffer and incubated with recombinant terminal transferase TdT enzyme at $37^{\circ} \mathrm{C}$. The sections were rinsed in washing buffer, washed in PBS, incubated with anti-digoxigenin conjugate, and then washed with PBS. The slides were incubated in 3, 3-diaminobenzidine tetrahydrochloride dihydrate (DAB) and washed with distilled water, stained with Mayer's haematoxylin. The slides were dehydrated with alcohol series, cleared with toluene and mounted with entellan (Merck, Darmstadt, Germany). In each section, randomly selected 20 seminiferous tubules were counted for TUNEL-positive cells. Seminiferous tubules contains three or more TUNEL + cells were evaluted and calculated to total seminiferous tubules.

All stained sections were evaluated and photographed with the digital camera (Olympus C-5060, Tokyo, Japan) of a photomicroscope (Olympus BX51, Tokyo, Japan).

\subsection{Transmission electron microscopic (TEM) preparation}

Approximately $3 \mathrm{~mm}^{3}$ tissue samples from the left testis were fixed into $2.5 \%$ glutaraldehyde in PBS $(0.1$ $\mathrm{M}, \mathrm{pH}$ 7.2), postfixed in $1 \%$ osmium tetroxide in PBS (0.1 M, pH 7.2), dehydrated in an increased series of ethanol and embedded in Epon 812 resin (Fluka, Sigma-Aldrich Chemica, Steinheim, Switzerland). Ultrathin sections were contrasted with uranyl acetate and lead citrate. The ultrathin sections were examined using a transmission electron microscope (JEOL 1200 EXII, Tokyo, Japan) and photographed with digital camera (Morada Soft Imaging System, Olympus, USA). 


\subsection{Biochemical Analysis}

\subsubsection{Malondyaldehyde and glutatione $H$ assays}

The half of the left testes samples were homogenized in ice cold $150 \mathrm{mM} \mathrm{KCl}$ for assignment of MDA and GSH levels.

MDA levels were analysed as lipid peroxidation products [45]. Results are expressed as nmol MDA/g tissue. GSH was determined by the spectrophotometric method using the Ellman's reagent [46]. Results are expressed $\mu \mathrm{mol} \mathrm{GSH} / \mathrm{g}$ tissue.

\subsubsection{Myeloperoxidase activity}

Tissue associated myeloperoxidase (MPO) activity was evaluated according to Hillegas et al. [47] method. Testis samples were homogenized in $50 \mathrm{mM}$ potassium phosphate buffer ( $\mathrm{PB}, \mathrm{pH} 6.0)$ and centrifuged at $41,400 \mathrm{~g}(10 \mathrm{~min})$, pellets were suspended in $50 \mathrm{mM}$ PBS containing $0.5 \%$ hexadecyltrimethylammonium bromide. MPO activity was evaluaated by measuring the $\mathrm{H}_{2} \mathrm{O}_{2}$-dependent oxidation of odianizidine $2 \mathrm{HCl}$. One unit of enzyme activity was described as the amount of MPO that causes alteration in absorbance of 1.0 unit/min at $460 \mathrm{~nm}$ and was expressed as unit/g tissue.

\subsubsection{Statistical analysis}

Data were analysed using one-way analysis of variance (ANOVA). Differences between groups were determined with Tukey's multiple comparisons test, and the data were expressed as mean \pm standard error of the mean (SEM). Significance of differences was taken at the level of $p<0.05$. Calculations were performed using Instant statistical analysis package (Prism 5.0 GraphPad Software, San Diego, CA, USA).

Acknowledgement: The authors thank the Marmara University Scientific Research Project Commission for their financial support (SAG-C-YLP-090414-0076).

Author contributions: Conception - N.Ö.Y., G.Ş., F.E.; Design - N.Ö.Y, G.Ş., F.E.; Supervision - G.Ş., F.E.; Resources N.Ö.Y., F.E.; Materials - N.Ö.Y., G.Ş., F.E.; Data Collection and/or Processing - N.Ö.Y., F.E.; Analysis and/or Interpretation - N.Ö.Y., G.Ş, F.E.; Literature Search - N.Ö.Y., F.E.; Writing Manuscript- N.Ö.Y., F.E.; Critical Review N.Ö.Y., G.Ş., F.E.

Conflict of interest statement: The authors declared no conflict of interest.

\section{REFERENCES}

[1] Sherif IO, Abdel-Aziz A, Sarhan OM. Cisplatin-induced testicular toxicity in rats: the protective effect of arjunolic acid. J Biochem Mol Toxicol. 2014; 28(11): 515-521. [CrossRef]

[2] Chinwe GS, Azuka OI, Adaeze NC. Resveratrol supplementation rescues pool of growing follicles and ovarian stroma from Cisplatin-induced toxicity on the ovary in Sprague-Dawley rats: An experimental study. Int J Reprod Biomed. 2018; 16(1): 19-30. [CrossRef]

[3] Chiang KC, Tsui KH, Chung LC, Yeh CN, Feng TH, Chen WT, Chang PL, Chiang HY, Juang HH. Cisplatin modulates B cell translocation gene 2 to attenuate cell proliferation of prostate carcinoma cells in both p53-dependent and p53independent pathways. Sci Rep. 2014; 4: 5511. [CrossRef]

[4] Khaled HM, Shafik HE, Zabhloul MS, Ghoneim M, Saber RA, Manie M, Enein HA, Megeed HA, Mansur O, Sherbini ME, Mahran TZ, Kalawee ME, Badran A, Ramadan SM. Gemcitabine and cisplatin as neoadjuvant chemotherapy for invasive transitional and squamous cell carcinoma of the bladder: Effect on survival and bladder preservation. Clin Genitourin Cancer. 2014; 12(5): e233-40. [CrossRef]

[5] Groh T, Hrabeta J, Khalil MA, Doktorova H, Eckschlager T, Stiborova M. The synergistic effects of DNA-damaging drugs cisplatin and etoposide witha histone deacetylase inhibitor valproate in high-risk neuroblastoma cells. Int J Oncol. 2015; 47(1): 343-352. [CrossRef]

[6] Kim MJ, Kim SM, Jung HA, Hong JY, Chang WJ, Choi MK, Kim HS, Sun JM, Park K, Ahn MJ. Efficacy and safety of cisplatin and weekly docetaxel in patients with recurrent or metastatic squamous cell carcinoma of the head and neck. Korean J Intern Med. 2018; Epub a head of print. [CrossRef]

[7] Şener G, Satiroglu H, Kabasakal L, Arbak S, Oner S, Ercan F, Keyer-Uysal M. The protective effect of melatonin on cisplatin nephrotoxicity. Fundam Clin Pharmacol. 2000; 14(6): 553-560. [CrossRef] 
[8] Kim SJ, Park C, Lee JN, Park R. Protective roles of fenofibrate against cisplatin induced ototoxicity by the rescue of peroxisomaland mitochondrial dysfunction. Toxicol Appl Pharmacol. 2018; 353: 43-54. [CrossRef]

[9] Li DW, Sun JY, Wang K, Zhang S, Hou YJ, Yang MF, Fu XY, Zhang ZY, Mao LL, Yuan H, Fang J, Fan CD, Zhu MJ, Sun BL. Attenuation of cisplatin-1nduced neurotoxicity by Cyanidin, a natural inhibitor of ROS-mediated apoptosis in PC12 Cells. Cell Mol Neurobiol. 2015; 35(7): 995-1001. [CrossRef]

[10] Patanè S. Cardiotoxicity: cisplatin and long-term cancer survivors. Int J Cardiol. 2014; 175(1): 201-202. [CrossRef]

[11] Liu M, Maselli J, Hales BF, Robaire B. The effects of chemotherapy with bleomycin, etoposide, and cis-platinum on telomeres in rat male germ cells. Andrology. 2015; 3(6): 1104-1112. [CrossRef]

[12] Marcon L, Hales BF, Robaire B. Reversibility of the effects of subchronic exposure to the cancer chemotherapeutics bleomycin, etoposide, and cisplatin on spermatogenesis, fertility, and progeny outcome in the male rat. J Androl. 2008; 29(4): 408-417. [CrossRef]

[13] Türk G, Ceribaşı AO, Sahna E, Ateşşahin A. Lycopene and ellagic acid prevent testicular apoptosis induced by cisplatin. Phytomedicine. 2011; 18(5): 356-361. [CrossRef]

[14] Tian M, Liu F, Liu H, Zhang Q, Li L, Hou X, Zhao J, Li S, Chang X, Sun Y. Grape seed procyanidins extract attenuates Cisplatin-induced oxidative stress and testosterone synthase inhibition in rat testes. Syst Biol Reprod Med. 2018; 64(4): 246-259. [CrossRef]

[15] Madhu P, Reddy KP, Reddy PS. Melatonin reduces oxidative stress and restores mitochondrial function in the liver of rats exposed to chemotherapeutics. J Exp Zool A Ecol Genet Physiol. 2015; 323(5): 301-308. [CrossRef]

[16] Sanchez-Gonzalez PD, Lopez-Hernandez FJ, Duenas M, Prieto M, Sanchez-Lopez E, Thomale J, Ruiz-Ortega M, Lopez-Novoa JM, Morales AI. Differential effect of quercetin on cisplatin-induced toxicity in kidney and tumor tissues. Food Chem Toxicol. 2017; 107(Pt A): 226-236. [CrossRef]

[17] Gusman J, Malonne H, Atassi G. A reappraisal of the potential chemopreventive and chemotherapeutic properties of resveratrol. Carcinogenesis. 2001; 22(8): 1111-1117.[CrossRef]

[18] Tatlidede E, Sehirli O, Velioğlu-Oğünc A, Cetinel S, Yeğen BC, Yarat A, Süleymanoğlu S, Sener G. Resveratrol treatment protects against doxorubicin-induced cardiotoxicity by alleviating oxidative damage. Free Radic Res. 2009; 43(3): 195-205. [CrossRef]

[19] Sener G, Topaloğlu N, Sehirli AO, Ercan F, Gedik N. Resveratrol alleviates bleomycin-induced lung injury in rats. Pulm Pharmacol Ther. 2007; 20(6): 642-649.[CrossRef]

[20] Heeba GH, Hamza AA, Hassanin SO. Induction of heme oxygenase-1 with hemin alleviates cisplatin-induced reproductive toxicity in male rats and enhances its cytotoxicity in prostate cancer cell line. Toxicol Lett. 2016; 264: 3850.[CrossRef]

[21] Coşkun N, Hatipoğlu MT, Ozoğul C, Korkmaz C, Akyol SN, Mıcılı SC, Arık GS, Erdoğan D. The protective effects of acetyl L-carnitine on testis gonadotoxicity induced by cisplatin in rats. Balkan Med J. 2013; 30(2): 235-241.[CrossRef]

[22] Köroğlu KM, Çevik Ö, Şener G, Ercan F. Apocynin alleviates cisplatin-induced testicular cytotoxicity by regulating oxidative stress and apoptosis in rats. Andrologia. 2019; 8: 13227. [CrossRef]

[23] Ju SM, Pae HO, Kim WS, Kang DG, Lee HS, Jeon BH. Role of reactive oxygen species in p53 activation during cisplatin-induced apoptosis of ratmesangial cells. Eur Rev Med Pharmacol Sci. 2014; 18(8): 1135-1141.

[24] Boroja T, Katanic J, Rosić G, Selakovic D, Joksimovic J, Misic D, Stankovic V, Jovicic N, Mihailovic V. Summer savory (Satureja hortensis L.) extract: Phytochemical profile and modulatin of cisplatin-induced liver, renal and testicular toxicity. Food Chem Toxicol. 2018; 118: 252-263. [CrossRef]

[25] Kilarkaje N, Mousa AM, Al-Bader MM, Khan KM. Antioxidants enhance the recovery of three cycles of bleomycin, etoposide, and cisplatin-induced testicular dysfunction, pituitary-testicular axis, and fertility in rats. Fertil Steril. 2013; 100(4): 1151-1159. [CrossRef]

[26] Işeri S, Ercan F, Gedik N, Yüksel M, Alican I. Simvastatin attenuates cisplatin-induced kidney and liver damage in rats. Toxicology.2007; 230(2-3): 256-264. [CrossRef]

[27] Amin A, Abraham C, Hamza AA, Abdalla ZA, Al-Shamsi SB, Harethi SS, Daoud S. A standardized extract of Ginkgo biloba neutralizes cisplatin-mediated reproductive toxicity in rats. J Biomed Biotechnol. 2012; 2012: 362049. [CrossRef]

[28] Abarikwu SO, Olufemi PD, Lawrence CJ, Wekere FC, Ochulor AC, Barikuma AM. Rutin, an antioxidant flavonoid, induces glutathione and glutathione peroxidase activities to protect against ethanol effects in cadmium-induced oxidative stress in the testis of adult rats. Andrologia. 2017; 49(7). [CrossRef] 
[29] Tekin G, İsbir S, Şener G, Çevik Ö, Çetinel Ş, Dericioğlu O, Arsan S, Çobanoğlu A. The preventive and curative effects of melatonin against abdominal aortic aneurysm in rats. J Vasc Surg. 2018; 67(5): 1546-1555. [CrossRef]

[30] Dasari S, Tchounwou PB. Cisplatin in cancer therapy: molecular mechanisms of action. Eur J Pharmacol. 2014; 740: 364-378.[CrossRef]

[31] Fouad AA, Qutub HO, Fouad AEA, Audeh AM, Al-Melhim WN. Epigallocatechin-3-gallate counters cisplatin toxicity of rat testes. Pharm Biol. 2017; 55(1): 1710-1714. [CrossRef]

[32] Gevrek F, Erdemir F. Investigation of the effects of curcumin, vitamin E and their combination in cisplatin-induced testicular apoptosis using immunohistochemical technique. Turk J Urol. 2018; 44(1): 16-23. [CrossRef]

[33] Yaman O, Topcu-Tarladacalisir Y. L-carnitine counteracts prepubertal exposure to cisplatin induced impaired sperm in adult rats by preventing germ cell apoptosis. Biotech Histochem. 2018; 93(3): 157-167. [CrossRef]

[34] Aksu EH, Kandemir FM, Özkaraca M, Ömür AD, Küçükler S, Çomaklı S. Rutin ameliorates cisplatin-induced reproductive damage via suppression of oxidative stress and apoptosis in adult male rats. Andrologia. 2017; 49(1). [CrossRef]

[35] Anand H, Misro MM, Sharma SB, Prakash S. Protective effects of Eugenia jambolana extract versus N-acetyl cysteine against cisplatin-induced damage in rat testis. Andrologia. 2015; 47(2): 194-208. [CrossRef]

[36] Hao Q, Xiao X, Zhen J, Feng J, Song C, Jiang B, Hu Z. Resveratrol attenuates acute kidney injury by inhibiting death receptor mediated apoptotic pathways in a cisplatin induced rat model. Mol Med Rep. 2016; 14(4): 3683-3689. [CrossRef]

[37] Wang J, He D, Zhang Q, Han Y, Jin S, Qi F. Resveratrol protects against Cisplatin-induced cardiotoxicity by alleviating oxidative damage. Cancer Biother Radiopharm. 2009; 24(6): 675-680. [CrossRef]

[38] Alturfan AA, Tozan-Beceren A, Sehirli AO, Demiralp E, Sener G, Omurtag GZ. Resveratrol ameliorates oxidative DNA damage and protects against acrylamide-induced oxidative stress in rats. Mol Biol Rep. 2012; 39(4): 4589-4596. [CrossRef]

[39] Yuluğ E, Türedi S, Karagüzel E, Kutlu O, Menteşe A, Alver A. The short term effects of resveratrol on ischemiareperfusion injury in rat testis. J Pediatr Surg. 2014; 49(3): 484-489. [CrossRef]

[40] Eleawa SM, Alkhateeb MA, Alhashem FH, Bin-Jaliah I, Sakr HF, Elrefaey HM, Elkarib AO, Alessa RM, Haidara MA, Shatoor AS, Khalil MA. Resveratrol reverses cadmium chloride-induced testicular damage and subfertility by downregulating p53 and Bax and upregulating gonadotropins and Bcl-2 gene expression. J Reprod Dev. 2014; 60(2): 115-127. [CrossRef]

[41] Archana D, Supriya C, Girish BP, Kishori B, Reddy PS. Alleviative effect of resveratrol on polyvinyl chloride-induced reproductive toxicity in male Wistar rats. Food Chem Toxicol. 2018; 116 (Pt B): 173-181. [CrossRef]

[42] Singh I, Goyal Y, Ranawat P. Potential chemoprotective role of resveratrol against cisplatin induced testicular damage in mice. Chem Biol Interact. 2017; 273: 200-211. [CrossRef]

[43] Reddy KP, Madhu P, Reddy PS. Protective effects of resveratrol against cisplatin-induced testicular and epididymal toxicity in rats. Food Chem Toxicol. 2016; 91: 65-72. [CrossRef]

[44] Erkanlı Şentürk G, Ersoy Canillioĝlu Y, Umay C, Demiralp-Eksioglu E, Ercan F. Distribution of Zonula Occludens-1 and Occludin and alterations of testicular morphology after in utero radiation and postnatal hyperthermia in rats. Int J Exp Pathol. 2012; 93(6): 438-449. [CrossRef]

[45] Beuge JA, Aust SD. Microsomal lipid peroxidation. Methods Enzymol. 1978; 52: 302-310. [CrossRef]

[46] Beutler, E. (1975). Glutathione in red blood cell metabolism. In: Beutler E (ed.). A Manuel of Biochemical Methods. $91 ; 112-144$.

[47] Hillegas LM, Griswold DE, Brickson B, Albrightson-Winslow C. Assesment of myeloperoxidase activity in whole rat kidney. J Pharmacol Methods.1990; 24: 285-295. [CrossRef]

This is an open access article which is publicly available on our journal's website under Institutional Repository at http://dspace.marmara.edu.tr. 